\title{
SUBACUTE AND CHRONIC INTUSSUSCEPTION IN INFANTS AND CHILDREN
}

\author{
BY \\ DUNCAN MACAULAY and THOMAS MOORE \\ From the Department of Child Health, Manchester University, \\ and the Duchess of York Hospital for Babies, Manchester
}

(RECEIVED FOR PUBLICATION NOVEMBER 9, 1954)

Most writers on the subject claim that chronic intussusception is rare in childhood. Thus Still (1921) stated that in children it occurs 'rarely indeed'; Monrad (1927) wrote: 'Chronic invaginations in my experience are extremely rare in small children'; Beaven (1929) noted that 'judging from the number of cases reported, chronic intussusception is an extremely rare disease in children'; and Nyborg (1943) stated that the condition 'is very rare in young children'. We have recently encountered two cases in infants within a short period and, as a result of our scrutiny of hospital records and of the literature, we do not think that this emphasis on rarity is justified.

\section{Case Reports}

Case 1. A boy of 5 months was admitted to the Duchess of York Hospital for Babies, Manchester, in May, 1954. He was the firstborn of healthy young parents and he had progressed satisfactorily until four weeks before admission. At that time he began to get attacks of 'colic', in which he screamed, drew up his legs and went pale. These episodes were brief $-a$ few minutes only-and between attacks he seemed quite well. For several days he had two or three such attacks each day without other symptoms. Thereafter he began to vomit and about the same time he developed what his mother described as 'black diarrhoea'. The diarrhoea and vomiting persisted as did the screaming attacks until he came into hospital. For a week or two before admission he was chesty and he became progressively more miserable and lost weight steadily. Several days before admission he had begun to refuse his feeds. Examination in the out-patient department showed a pale, alert infant who had recently lost weight. Apart from some redness of the throat nothing abnormal was discovered. When he was re-examined in the ward an hour or two later two masses were felt in the abdomen, one in the right flank and the other under the left costal margin. It was at first thought that these were the kidneys. No abnormalities were found in the urine and the blood urea was normal. In the first 24 hours in hospital the infant vomited several of his feeds and passed a dark, frothy stool which gave a positive benzidine reaction. Repeated examination of the abdomen by several observers led to conflicting opinions. At times there was nothing abnormal to be felt, while at others a mass of varying size could be palpated, sometimes on the right side, sometimes in the epigastrium. A barium enema was administered and the diagnosis was clearly revealed (Fig. 1). Laparotomy was performed on the

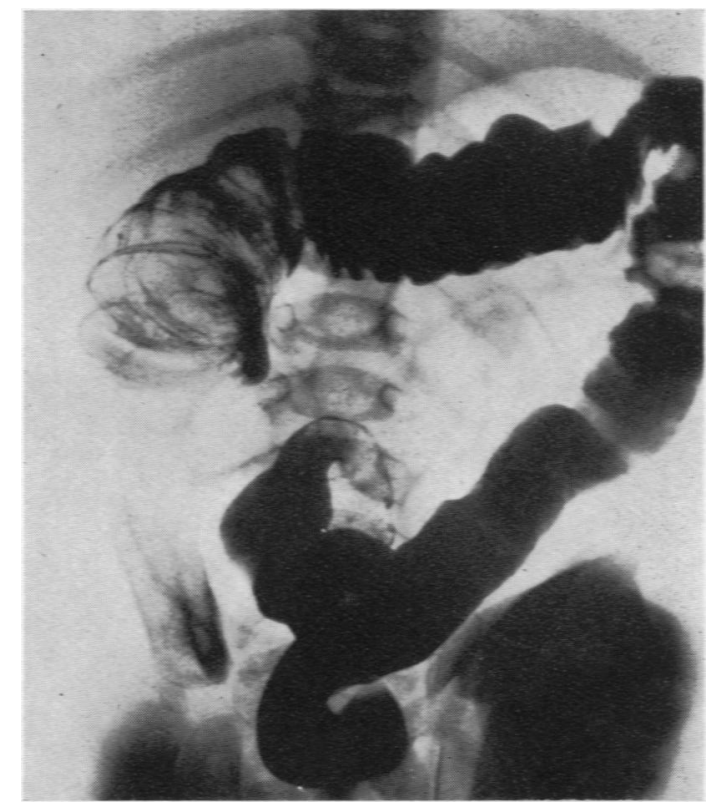

Fig. 1.-Barium enema in Case 1 showing typical cupola appearance.

third day. There was some excess of free fluid in the peritoneal cavity, the small bowel was somewhat dilated and many enlarged glands were present in the mesentery. Along the ascending colon a typical intussusception could be felt. While the bowel was being delivered this reduced itself except for an invagination of the caput caeci which was reduced by digital pressure. Marked thickening of the ileo-caecal valve could be felt through the caecum. 
The appendix was bound down to the lateral wall of the caecum and enveloped in fine adhesions. It was thought that this tethering of the caecum by the appendix was the reason why the intussusception had not progressed in the usual manner. Appendicectomy was carried out. Apart from an attack of diarrhoea due to a specific coliform organism on the tenth day the subsequent course was satisfactory, and when last seen the child had a soundly healed wound, no symptoms, and was gaining weight.

Case 2. A girl was first seen at the age of 3 months because she had a large tongue which protruded all the time. She appeared to be a cretin and treatment with thyroid was begun. She progressed fairly well for the next three months and then began to vomit once or twice a day. This was associated with attacks of abdominal pain which were brief and between which she seemed to be well. This state persisted for three weeks during which time the stools were dark brown, slimy and loose. The day before she was admitted (at the age of 7 months) the attacks of 'colic' were much more frequent and severe and in some of them she went into opisthotonos. From the onset of the vomiting she had lost $\frac{1}{2} \mathrm{lb}$. in weight. When she was examined a mass was felt in the left hypochondrium. It was difficult to define and was thought to be the spleen. The liver was easily palpable. A bowel wash-out was given and thereafter the mass could no longer be felt. A barium enema was attempted on two occasions but the barium was repeatedly rejected and the examinations were inconclusive. In the course of the next few days the infant developed a respiratory infection which was treated with penicillin. Vomiting persisted and, though she did not have any attacks of severe pain, she was occasionally cross and fretful without apparent cause. She tended to be constipated

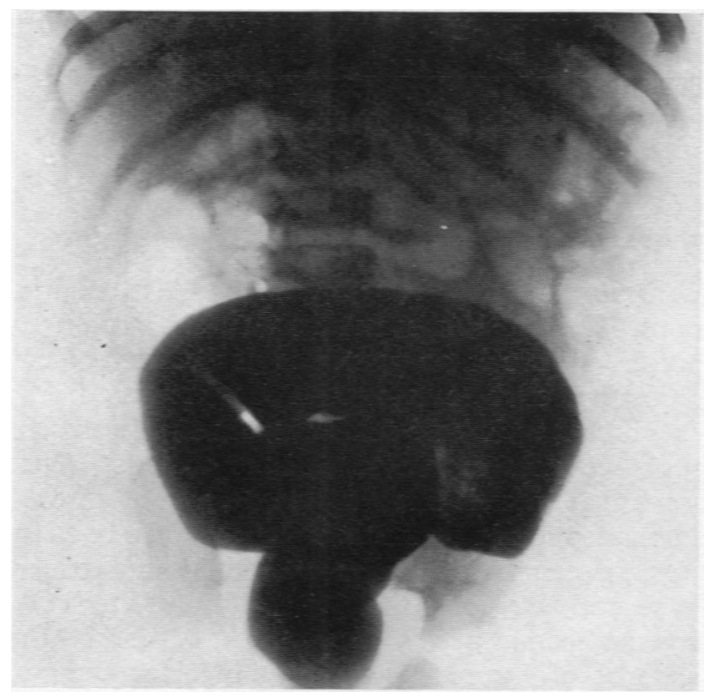

Fig. 2.-Barium enema in Case 2 showing complete obstruction to flow of barium at lower end of descending colon. and required aperients but the stools were not otherwise abnormal. For three weeks she remained much the same and then suddenly became acutely and seriously ill. She vomited continuously, passed frequent small stools

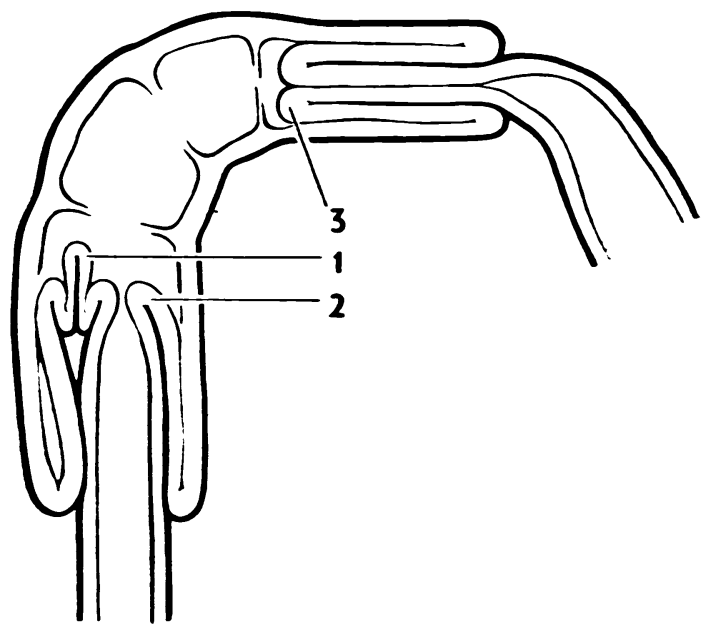

Fig. 3.- Condition found at operation in Case 2, showing three intussusceptions present at the same time.

consisting almost entirely of blood and mucus, and rapidly became drowsy and dehydrated. A mass could be felt in the left hypochondrium similar to that felt at the time of admission. A barium enema revealed complete obstruction to the flow of the barium at the lower end of the descending colon (Fig. 2). Laparotomy was performed six weeks after the onset of the first abdominal symptoms. In the left side of the abdomen a mass was felt which had the characteristics of an intussusception but which was pointing upwards instead of downwards. The bowel was delivered and in the middle of the transverse colon a retrograde colo-colic intussusception was found. This was reduced without much difficulty. A further intussusception was found in the ascending colon, the apex having travelled as far as the hepatic flexure. Reduction of this second intussusception was easily accomplished as far as the caecum, where it was found that the appendix had intussuscepted on itself and was invaginated into the caecum. The appendicular intussusception was irreducible and during attempts to reduce it the caecum was perforated. Resection of the appendix with a small part of the caecum was performed and the resulting defect closed in two layers. Fig. 3 represents the state of affairs in this child's abdomen at the time of operation. There were in fact three intussusceptions, of which the appendicular one was probably of long standing, the ileocolic one was probably recurring, and the colo-colic one of recent onset and the cause of the sudden deterioration in the child's condition. The post-operative course was uneventful apart from an attack of chickenpox and there have been no further abdominal symptoms. 


\section{Discussion}

The first of these cases presented no unusual features apart from the long duration of the symptoms. The second case, on the other hand, was quite remarkable not only for the length of the history but for the presence of three intussusceptions at the same time, the occurrence of a retrograde intussusception (an extremely uncommon event during life) and the appendicular intussusception (also a rare occurrence).

In order to discover how frequently intussusceptions of such prolonged course occur in children the records of the three hospitals in Manchester which admit large numbers of children were examined. The numbers are shown in Table 1. In the

TABLE 1

INTUSSUSCEPTION IN THE THREE MAIN CHILDREN'S HOSPITALS IN MANCHESTER

\begin{tabular}{|c|c|c|c|c|c|c|c|c|c|}
\hline $\begin{array}{l}\text { Hos- } \\
\text { pital }\end{array}$ & $\begin{array}{l}\text { Up } \\
\text { to } \\
1948\end{array}$ & 1948 & 1949 & 1950 & 1951 & 1952 & 1953 & $\begin{array}{l}\text { To } \\
\text { mid- } \\
1954\end{array}$ & Total \\
\hline $\begin{array}{l}\text { R.M.C.H. } \\
\text { B.H.H. } \\
\text { D.Y.H. }\end{array}$ & 29 & $\begin{array}{r}17 \\
1\end{array}$ & $\begin{array}{r}5 \\
23 \\
12\end{array}$ & $\begin{array}{r}12 \\
29 \\
7\end{array}$ & $\begin{array}{r}10 \\
19 \\
8\end{array}$ & $\begin{array}{l}10 \\
26 \\
10\end{array}$ & $\begin{array}{r}11 \\
20 \\
4\end{array}$ & $\begin{array}{r}4 \\
11\end{array}$ & \\
\hline Total & 29 & 18 & 40 & 48 & 37 & 46 & 35 & 20 & 273 \\
\hline
\end{tabular}

five years for which complete records are available the average number of cases of intussusception per year is 41 . This is comparable to the numbers reported by Spence and Court (1950) in Newcastle (239 cases in six years).

It was soon obvious from a scrutiny of these records that a definition of what constitutes a case of subacute or chronic intussusception was required. There is evidence from the early literature, before surgical treatment was practised, that the average duration of the illness from the onset of symptoms until death in cases of acute intussusception was four days (Hutchinson, 1874). Pilz (1870) reviewed all the cases of intussusception in children reported up till that date and he noted that in the great majority death occurred between the second and sixth days. It seems clear that the ordinary case of acute intussusception will die within a week of the onset unless treated and that survival beyond the sixth day constitutes evidence of chronicity. This is in accord with the classification of Rafinesque (1878) who divided intussusception into four types, hyperacute (dying within two days of the onset), acute (dying within a week), subacute (surviving for seven to 14 days) and chronic (surviving more than 14 days). The records of the 273 Manchester cases have been analysed from this point of view. Table 2 gives the results of this analysis.
TABLE 2

INCIDENCE OF SUBACUTE AND CHRONIC INTUSSUSCEPTION IN MANCHESTER SERIES

\begin{tabular}{|c|c|c|c|c|}
\hline & $\begin{array}{l}\text { Total } \\
\text { Cases }\end{array}$ & $\begin{array}{l}\text { Subacute - } \\
7-14 \text { Days }\end{array}$ & $\begin{array}{l}\text { Chronic - } \\
\text { Over } 14 \text { Days }\end{array}$ & $\begin{array}{c}\text { Subacute }- \\
\text { Chronic }\end{array}$ \\
\hline $\begin{array}{l}\text { Under } 1 \text { yr. } \\
\text { Over } 1 \text { yr. } \\
\text { All ages }\end{array}$ & $\begin{array}{r}195 \\
78 \\
273\end{array}$ & $\begin{array}{l}2 \\
7 \\
9\end{array}$ & $\begin{array}{l}5 \\
1 \\
6\end{array}$ & $\begin{array}{r}7(3.6 \%) \\
8(10 \cdot 3 \%) \\
15(5 \cdot 5 \%)\end{array}$ \\
\hline
\end{tabular}

As a check on these figures a number of large reported series have been examined. Series based on less than 100 cases have been ignored as likely to be misleading in assessing the incidence of a rather uncommon feature like chronicity. Fifteen reports were satisfactory as far as total numbers were concerned but in only six of them was there information about the length of history suitable for the present purpose (Pitts, 1901; Koch and Oerum, 1912; Clubbe, 1921; Stallman, 1926; Ladd and Gross, 1934; Nyborg, 1943). These series comprise a total of 1,352 cases, and Table 3 shows the incidence of chronic intussusception in this number. 'Chronic' in this case indicates survival beyond six days from the onset; it was not possible on the available data to subdivide these further into subacute and chronic types. The agreement with the Manchester figures is close and it seems justifiable to combine the two sets of figures as shown in the last column of Table 3 . It then appears that in

TABLE 3

INCIDENCE OF 'CHRONIC' INTUSSUSCEPTION IN SIX REPORTED SERIES COMPARED WITH MANCHESTER SERIES

\begin{tabular}{|c|c|c|c|c|}
\hline & & Manchester & Former Series & Total \\
\hline $\begin{array}{l}\text { Under } 1 \text { yr. } \\
\text { Over } 1 \text { yr. .. }\end{array}$ & $\begin{array}{l}\cdots \\
\cdots\end{array}$ & $\begin{array}{l}7 \text { of } 195 \\
(3.6 \%) \\
8 \text { of } 78 \\
(10.3 \%)\end{array}$ & $\begin{array}{c}29 \text { of } 956 \\
(3.0 \%) \\
41 \text { of } 396 \\
(10.4 \%)\end{array}$ & $\begin{array}{l}36 \text { of } 1,151 \\
(3.1 \%) \\
49 \text { of } 474 \\
(10 \cdot 3 \%)\end{array}$ \\
\hline All ages $\ldots$ & $\cdots$ & $\begin{array}{c}15 \text { of } 273 \\
(5 \cdot 5 \%)\end{array}$ & $\begin{array}{c}70 \text { of } 1,352 \\
(5 \cdot 2 \%)\end{array}$ & $\begin{array}{l}85 \text { of } 1,625 \\
(5 \cdot 2 \%)\end{array}$ \\
\hline
\end{tabular}

infants under 1 year about $3 \%$, and in older children about $10 \%$, of intussusceptions run a prolonged course. If this is accepted the probability of encountering such a case can be estimated. In Manchester each year there are about 40 cases of intussusception of which 30 are infants. That means that there is likely to be one case of chronic intussusception in an infant each year. Since these cases are seen in three different hospitals and treated by several surgeons the probability of any one surgeon seeing a case is small. Although the incidence of chronicity is greater in older children the total number of cases of intussusception in them is so much smaller that again the chance of any one 
person seeing a case is slight. The frequency works out at about one case a year in the city of Manchester.

These figures do not support the opinions quoted in the introductory paragraph about the extreme rarity of this disease in children. However, there is further support for our position in the paper of Birkenfeld (1926). He was able to find reports of 160 cases of intussusception in children under the age of 14 years in whom the duration of symptoms was 14 days or longer. Of this total 31 were infants under the age of 1 year. Since Birkenfeld wrote there have been several papers on chronic intussusception in children, most of which treat the condition as one of great rarity. Birkenfeld's paper does not seem to be as widely known as it ought to be.

The symptoms in the cases occurring in Manchester are shown in Fig. 4. They do not differ

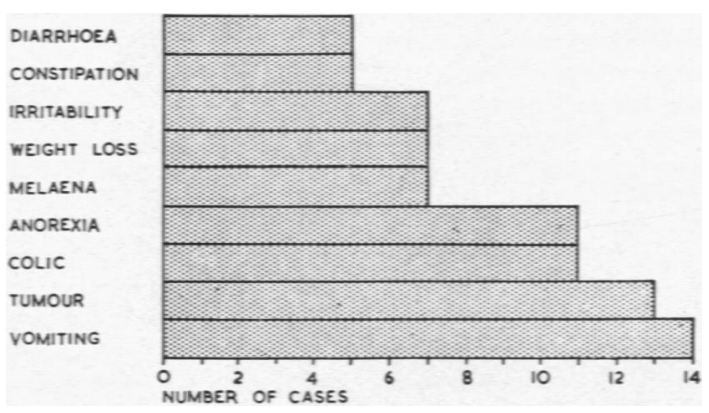

Fig. 4.-Analysis of symptoms in 15 cases of subacute and chronic intussusception.

appreciably from those to be expected in any case of intussusception and we should like to emphasize the contention of Birkenfeld and of Garvie and Kemp
(1945) that the most significant feature of the history in these cases is the occurrence of intermittent, colicky abdominal pain. 'The only reliable clinical feature is a story of repeated attacks characterized by the sudden onset of gripping abdominal pain. All other symptoms of intussusception may be absent and are unreliable' (Garvie and Kemp).

\section{Summary}

Two cases of intussusception in infants, of prolonged duration, four and six weeks respectively, are reported in detail.

From an analysis of hospital records it is concluded that the incidence of prolonged intussusception is about $3 \%$ of all cases in infants under 1 year of age and about $10 \%$ in children over that age. These figures are in substantial agreement with those derived from a review of the literature.

Subacute and chronic intussusception in infants and children is not such a rare condition as is often claimed.

We are indebted to the medical staffs of the hospitals whose records we have consulted for permission to do so.

\section{Refienacas}

Beaven, P. W. (1929). Amer. J. Dis. Child, 37, 373.

Birkenfeld, W. (1926). Brwor' Beitr. Kliv. Chir., 138, 521.

Clubbe, C. P. B. (1921). The Diagmosis and Treatment of Intussusception, 2nd ed. London.

Garvie, J. M. and Kemp, F. H. (1945). Archives of Disease in Childhood, 20, 73.

Hutchinson, J. (1874). Med.-chir. Trans., 57, 31.

Koch, A. and Oerum, H. P. T. (1912). Edinb. med. J., 9, 227.

Ladd, W. E. and Gross, R. E. (1934). Arch. Surt., Chicago, 29, 365.

Monrad, S. (1927). Acta poediat., Uppsala, 6, 31.

Nyborg, S. (1943). Acta chir. scand, Suppl. 80.

Pik C. (1870). Jb. Kinderheilk., 3, 6.

Pitts, B. (1901). Brit. med. J., 2, 574.

Rafinesque, F. G. (1878). Érude sur les Invaginations Intestinales Choriones. Paris

Spence, J. and Court, D. (1950). Brit. med. J., 2, 920.

Stallman, J. F. H. (1926). Ano. Surg., 84, 735.

Still, G. F. (1921). Arch. Pediat., 38, 174. 